\title{
Place-based social contact and mixing: a typology of generic meeting places of relevance for infectious disease transmission
}

\author{
M. STRÖMGREN ${ }^{1}$, E. HOLM ${ }^{1}$, Ö. DAHLSTRÖM ${ }^{2}$, J. EKBERG $^{3,4}$, \\ H. ERIKSSON ${ }^{5}$, A. SPRECO ${ }^{3,5}$ AND T. TIMPKA ${ }^{3,4,5}$ \\ ${ }^{1}$ Department of Social and Economic Geography, Umeå University, Umeå, Sweden \\ ${ }^{2}$ Department of Behavioural Sciences and Learning, Linköping University, Linköping, Sweden \\ ${ }^{3}$ Department of Medical and Health Sciences, Linköping University, Linköping, Sweden \\ ${ }^{4}$ Unit for Health Analyses, Östergötland Healthcare Region, Linköping, Sweden \\ ${ }^{5}$ Department of Computer and Information Science, Linköping University, Linköping, Sweden
}

Received 16 December 2016; Final revision 28 April 2017; Accepted 18 May 2017; first published online 19 June 2017

\section{SUMMARY}

This study aims to develop a typology of generic meeting places based on social contact and mixing of relevance for infectious disease transmission. Data were collected by means of a contact diary survey conducted on a representative sample of the Swedish population. The typology is derived from a cluster analysis accounting for four dimensions associated with transmission risk: visit propensity and its characteristics in terms of duration, number of other persons present and likelihood of physical contact. In the analysis, we also study demographic, socio-economic and geographical differences in the propensity of visiting meeting places. The typology identifies the family venue, the fixed activity site, the family vehicle, the trading plaza and the social network hub as generic meeting places. The meeting place typology represents a spatially explicit account of social contact and mixing relevant to infectious disease modelling, where the social context of the outbreak can be highlighted in light of the actual infectious disease.

Key words: Infectious disease, epidemiology, modelling.

\section{INTRODUCTION}

In recent decades, technological progress and forced migration have substantially altered interpersonal contact patterns and social diffusion processes at the global level. Developments in transportation - in particular air travel - have significantly contributed to reducing the friction of distance. In parallel, armed conflicts have led to that situation where millions of people have been forced to leave their homes to find

\footnotetext{
* Author for correspondence: M. Strömgren, Department of Geography and Economic History, Umeå University, 90187 Umeå, Sweden.

(E-mail: magnus.stromgren@umu.se)
}

temporary or permanent residence in a new region, country or even continent. These developments have given rise to challenges in other societal areas; for example, infectious disease control [1, 2]. Information and computer technology have increasingly been used to comprehend and respond to these challenges. Mathematical models and simulations have emerged as important methodological approaches for charting and understanding the population-level spread of infectious diseases, for example, tuberculosis [3-6] and influenza [7-11]. In such analyses, sound representations concerning social structures and interpersonal contacts need to be made, in addition to accurate estimates of disease natural history $[12,13]$. 
Spatial proximity and neighbourhood effects constitute central components in shaping the outcome in social diffusion processes [14]. However, such geographical resistance to spread tends to coincide with patterns that are more hierarchical in nature, facilitated by infrastructure and gravitating towards centres of population distribution [15]. Furthermore, social diffusion is mediated by individual demographic and socio-economic factors (such as age, sex and education level) through their influence on time use, activity patterns and interpersonal contact. In infectious disease epidemiology, the relative importance of such concrete (denoting physical locations) $v s$ abstract (denoting, for instance, education level) representations of populations and communities has been debated for almost two centuries [16]. Regarding the structuring of social contacts and mixing patterns relevant for infectious disease transmission, age has generally been shown to be a pivotal individual characteristic [17, 18]. Substantial disparities in how males and females allocate their time have also been reported [19], with females exhibiting a higher number of interpersonal contacts when professional contacts are excluded [17]. In addition, educational level is relevant in this context, not only as a potential influence as such, but also by its strong association with employment in particular. For instance, Danon et al. [20] report marked differences in interpersonal contact by occupation.

However, how social contacts and mixing patterns of relevance for infectious disease transmission are conditioned by the location and characteristics of meeting places in the geographical environment has only been studied to a relatively small extent. An empirically verified, spatially explicit representation of meeting places thus has the potential to improve the modelling of infectious disease transmission, compared with approaches accounting only for the effect of individual demographic and socio-economic factors. The aim of this study is to develop a typology of generic meeting places based on social contact and mixing of relevance for infectious disease transmission. The typology is derived from an analysis accounting for four dimensions associated with transmission risk: visit propensity and its characteristics in terms of duration, number of other persons present and likelihood of physical contact. In the analysis, we also study demographic, socio-economic and geographical differences in the propensity of visiting meeting places.

\section{METHODS}

The study is based on a cross-sectional contact diary survey on time use and interpersonal contacts conducted on a representative sample of the Swedish population. The data were collected by means of telephone interviews in the first quarter of 2012. A random sample of 1011 persons was drawn from all persons aged 20-90 years residing in Sweden. The persons in the sample received a letter via postal mail, explaining the purpose of the survey and inviting them to participate. The document informed the addressees that they would be contacted by telephone on a specified day, and then asked to account for the whereabouts and contacts the day before the call pertaining to themselves and any children in the household. ${ }^{1}$ Contact attempts were made based on available home and/or cell telephone numbers. When a person was not reached on the first call occasion, at least nine additional contact attempts were made before that individual was designated unreachable. ${ }^{2}$

\section{Data collection}

We recorded detailed information on the adult respondents' physical contacts for up to three places where the most time had been spent, as well as travelrelated time use and contact information. In order for a meeting between a respondent and another person to qualify as a 'physical contact', at least a physical touch was required. Consequently, solely conversational encounters were not registered as constituting physical contact. The places reported were classified as belonging to one of 16 specified generic place types; or coded as 'some other type of place'. If more than three place types had been visited, five attempts were made to record information from one additional type of place, randomly selected from the 13 remaining categories. This simplified survey template, producing detailed information on one to six place types, required an average time of approximately $20 \mathrm{~min}$ per completed telephone interview. The respondents also answered on behalf of up to two randomly selected children, accounting for up to three places where most time had been spent and physical contact occurring there. Although the survey was

1 These dates were selected so that each day of the week was distributed approximately equally among the potential respondents.

2 If potential respondents were reached at a later date than originally intended, they were given the option of accounting for either the initially specified day, or the day before the time of the successful contact attempt. 
primarily designed to collect information regarding the specified day, a number of additional questions of both a general and health-specific nature were included, some of which are used in this study.

\section{Response rates, dropout analysis and representativeness}

In the survey, 443 out of 1011 individuals submitted completed questionnaires, a response rate of $43 \cdot 8 \%$. When taking into account only the 757 persons reached by telephone, the participation rate was considerably higher $(58 \cdot 5 \%)$. The most common reason for declining to take part in the survey was time constraints. There were 288 children living in the respondents' households, of which $251(87 \cdot 2 \%)$ were included in the survey.

A dropout analysis was performed based on the adult respondents' sex, age and geographical location (Table 1). In the entire sample, the response rate was particularly high among elderly persons (54.4\%) and individuals residing in small labour market regions $(51 \cdot 4 \%)$. Among potential respondents reached by telephone, it was instead the youngest age category that exhibited the highest age-based response rate $(64 \cdot 1 \%)$. This implies that although young people were comparatively harder to reach by phone, they were actually more inclined to take part in the survey if reached.

The representativeness of the adult respondents in relation to the Swedish population in the corresponding age range of 20-90 years was also examined, taking into account not only sex, age and geographical location, but also education level. We used $\chi^{2}$ goodness-of-fit tests to make the comparisons; standardised residual values outside the range -1.96 to 1.96 were regarded as contributing to significant deviations. Significant differences relative to the reference population was found in terms of age and education. In the test of age representativeness, $\chi^{2}(\mathrm{df}=3, n$ $=443)=8 \cdot 35, P=0 \cdot 039$. In line with the result of the dropout analysis, the residual values show that the age category $65-90$ years is especially prevalent in our data. For education level, $\chi^{2}(\mathrm{df}=1, n=443)=$ $23 \cdot 42, P<0 \cdot 001$; the residuals reveal overrepresentation of people with high education.

Such overrepresentation may cause problems regarding the possibility of drawing general conclusions from the study. However, in evaluating this potential problem, effect size rather than significance is a more informative measure; especially as $\chi^{2}$ tests are sensitive to large sample sizes. We used Cramér's $V$ as a measure of effect size. For the age category $\chi^{2}$ test, $V=0.08$, and in the test of representativeness of education level, $V=0 \cdot 23$; both values representing small effects [21]. Thus, although elderly and highly educated individuals are especially prevalent in our data, the impact of these deviations from the reference population is of small magnitude.

\section{Data analysis}

Three related aspects of time use, activity patterns and interpersonal contact were investigated: places visited during the course of a typical day, the characteristics of such visits and the central relational perspective of who meets whom there. Although the survey initially distinguished between 17 types of meeting places, those visited by $<5 \%$ of the study participants were excluded from further analysis. The 12 remaining categories were: (1) home, (2) work, (3) pre-school and (4) compulsory or upper secondary school; transport and movement by (5) car and (6) public transport, as well as in (7) public urban space; the shopping facilities (8) convenience and (9) large or specialist store; and leisure destinations in the form of visiting (10) friends and relatives, (11) restaurants and (12) sport venues.

The individual demographic and socio-economic characteristics taken into account in the analysis were sex, age and (for adults) education level. The study participants were evenly distributed between males and females, comprising $51 \cdot 0 \%$ and $49 \cdot 0 \%$ of the research population, respectively. Concerning age, we distinguished between six age classes: 0-6 years $(15 \cdot 8 \%$ of the study participants), 7-19 years $(19 \cdot 0 \%), 20-29$ years $(10 \cdot 7 \%), 30-49$ years $(22 \cdot 2 \%)$, $50-64$ years $(13 \cdot 7 \%)$ and $65-90$ years $(18 \cdot 6 \%)$. In our study, somewhat less than half of the adult respondents $(44 \cdot 2 \%)$ reported having some kind of higher education.

Among the aspects of geographical location that influence social contacts and mixing patterns, the urban-rural dichotomy is central. Accessibility to amenities, such as employment, services and leisure, varies across space; regional population density is related to the diversity and number of, as well as distance to, available facilities that could potentially function as arenas for daily interaction [22]. This geographical dimension was operationalised as the size of the labour market region in which the respondents resided. The labour market regions $(N=75)$ are formed by aggregating Sweden's 290 municipalities 
Table 1. Response rates (\%) for the entire sample $(\mathrm{n}=1011)$ and the subset reached by telephone $(\mathrm{n}=757)$ by sex, age and geographical location

\begin{tabular}{llll}
\hline \hline \multirow{2}{*}{ Variable } & & \multicolumn{2}{l}{ Response rate (\%) } \\
\cline { 3 - 3 } Sex & Category & Entire sample & Subset reached by telephone \\
& Male & $42 \cdot 7$ & $59 \cdot 9$ \\
Age & Female & $45 \cdot 1$ & $57 \cdot 1$ \\
& 20-29 years & $40 \cdot 0$ & $64 \cdot 1$ \\
& 30-49 years & $40 \cdot 8$ & $58 \cdot 4$ \\
Geographical location & 50-64 years & $40 \cdot 6$ & $54 \cdot 3$ \\
& 65-90 years & $54 \cdot 4$ & $59 \cdot 4$ \\
Overall & Small labour market region & $51 \cdot 4$ & $65 \cdot 1$ \\
& Medium-sized labour market region & $45 \cdot 3$ & $59 \cdot 4$ \\
\hline \hline
\end{tabular}

based on commuting patterns [23]. Labour market region population size is highly correlated with actual regional population density $(P=0 \cdot 85)$. We distinguished between three categories of labour market regions: small $(<100000$ inhabitants), medium-sized (100 000-1 000000$)$ and large (>1 000000$)$. A majority of the respondents $(53.5 \%)$ lived in large labour market regions, $35.3 \%$ in medium-sized regions and $11 \cdot 2 \%$ in small regions.

In examining who visits different places during the course of a typical day, we compared visit propensity by individual attributes and geographical location to the corresponding averages. Specifically, the proportion of all respondents who frequented a specific type of place was subtracted from the proportion of groups of participants who did so. This yields numbers that express, in percentage points, the degree to which the various groups of study participants were more (positive number) or less (negative number) inclined to visit the specific places compared with the corresponding averages. Notable differences from the mean values were identified based on Wilson confidence intervals [24].

The typology of generic meeting places is created by means of a cluster analysis that identifies place types with similar characteristics. The analysis takes into account four meeting place dimensions associated with transmission risk: visit propensity and its characteristics in terms of duration, number of other persons present and likelihood of physical contact. The specific form of cluster analysis used is hierarchical cluster analysis based on standardised versions of the included variables, using Ward's method and a squared Euclidean distance measure. Squared Euclidean distance is a commonly used distance measure for scale data, and Ward's method has the benefit of providing comparatively high statistical power. The clustering technique used is agglomerative in character; at the outset, each observation (i.e. meeting place) is a cluster of its own; observations are subsequently iteratively grouped together or not based on their degree of (dis)similarity [25]. The final number of clusters was determined by interpreting changes in the distance coefficient, as reported in the resulting agglomeration schedule. ${ }^{3}$

\section{RESULTS}

The home was the meeting place reported to be visited by the largest proportion of participants $(95.0 \%)$ on the day surveyed (Table 2). The next most common place was a car, reported by $58.7 \%$. Thereafter, the respondents had to a similar extent visited a large or specialist store $(24 \cdot 1 \%)$, been at work $(21 \cdot 2 \%)$ and visited friends and relatives $(21.0 \%)$. Other place types frequented by at least $5 \%$ of the study participants were public transport $(16 \cdot 3 \%)$, compulsory or upper secondary school $(12 \cdot 0 \%)$, sports venue $(11 \cdot 5 \%)$, restaurant $(9 \cdot 4 \%)$, pre-school $(8 \cdot 6 \%)$, public urban space $(6 \cdot 6 \%)$ and convenience store $(5 \cdot 2 \%)$.

\section{Meeting place visit propensity}

As expected, meeting place visit propensity was highly stratified by age (Table 2). The youngest study participants $(0-6$ years) tended to be in pre-school $(25.9$

3 As a form of sensitivity analysis, we subsequently repeated the cluster analysis procedure using an additional linkage method and distance measure: between-groups linkage and Euclidean distance, respectively. For two out of the three additional analyses conducted, the preferred cluster solution was the same as the one used in the paper. 


\begin{tabular}{|c|c|c|c|c|c|c|c|c|c|c|c|}
\hline \multirow[b]{2}{*}{ Domain } & \multirow[b]{2}{*}{ Meeting place } & \multirow[b]{2}{*}{$\begin{array}{l}\text { Total } \\
(n=694)\end{array}$} & \multicolumn{6}{|l|}{ Age } & \multicolumn{3}{|c|}{ Regional population density } \\
\hline & & & $\begin{array}{l}0-6 \\
\text { years }\end{array}$ & $\begin{array}{l}7-19 \\
\text { years }\end{array}$ & $\begin{array}{l}20-29 \\
\text { years }\end{array}$ & $\begin{array}{l}30-49 \\
\text { years }\end{array}$ & $\begin{array}{l}50-64 \\
\text { years }\end{array}$ & $\begin{array}{l}65-90 \\
\text { years }\end{array}$ & Low & Medium & High \\
\hline \multirow[t]{4}{*}{ Home, work and school } & Home & $95 \cdot 0$ & $+0 \cdot 5$ & $-7 \cdot 1 * * *$ & -1.8 & $+1 \cdot 8$ & $+2 \cdot 9$ & $+3 \cdot 4 *$ & $-0 \cdot 1$ & $+0 \cdot 1$ & $-0 \cdot 1$ \\
\hline & Work & $21 \cdot 2$ & $-21 \cdot 2^{* * *}$ & $-18 \cdot 9^{* * *}$ & $+13 \cdot 9 * * *$ & $+30 \cdot 7 * * *$ & $+11 \cdot 4 * * *$ & $-15 \cdot 8^{* * *}$ & $+1 \cdot 9$ & -0.8 & $+0 \cdot 1$ \\
\hline & Pre-school & $8 \cdot 6$ & $+25 \cdot 9 * * *$ & $-6 \cdot 4 * *$ & $-3 \cdot 2$ & $-0 \cdot 2$ & $-8 \cdot 6^{* *}$ & $-7 \cdot 1^{* *}$ & $+5 \cdot 5^{*}$ & $+1 \cdot 2$ & -1.9 \\
\hline & $\begin{array}{l}\text { Compulsory or upper } \\
\text { secondary school }\end{array}$ & $12 \cdot 0$ & $-9 \cdot 2 * * *$ & $+44 \cdot 9 * * *$ & $-9 \cdot 3 * *$ & $-11 \cdot 3 * * *$ & $-10 \cdot 9 * * *$ & $-11 \cdot 2^{* * *}$ & $-9 \cdot 4 * *$ & $-1 \cdot 4$ & $+2 \cdot 8^{*}$ \\
\hline \multirow[t]{3}{*}{ Transport and movement } & Car & $58 \cdot 7^{\mathrm{a}}$ & $\mathrm{n} / \mathrm{a}$ & $\mathrm{n} / \mathrm{a}$ & $-4 \cdot 2$ & $+6 \cdot 7$ & $+2 \cdot 4$ & $-7 \cdot 5$ & $+17 \cdot 2 * *$ & $+7 \cdot 2^{*}$ & $-9 \cdot 4 * * *$ \\
\hline & Public transport & $16 \cdot 3^{\mathrm{a}}$ & $\mathrm{n} / \mathrm{a}$ & $\mathrm{n} / \mathrm{a}$ & $+3 \cdot 4$ & $+2 \cdot 0$ & $-3 \cdot 7$ & $-1 \cdot 6$ & $-12 \cdot 6^{* *}$ & $-9 \cdot 0^{* * *}$ & $+9 \cdot 5^{* * *}$ \\
\hline & Public urban space & $6 \cdot 6$ & $-3 \cdot 9$ & $-2 \cdot 8$ & $+0 \cdot 2$ & $+3 \cdot 8^{*}$ & $+0 \cdot 8$ & $+1 \cdot 2$ & $-5 \cdot 3^{*}$ & $+1 \cdot 2$ & $+0 \cdot 4$ \\
\hline \multirow[t]{2}{*}{ Shopping } & Convenience store & $5 \cdot 2$ & $-5 \cdot 2 * *$ & $-5 \cdot 2 * *$ & $+2 \cdot 9$ & +1.9 & $+0 \cdot 1$ & $+5 \cdot 7^{* * *}$ & $+2 \cdot 5$ & $+1 \cdot 7$ & $-1 \cdot 7$ \\
\hline & Large or specialist store & $24 \cdot 1$ & $-13 \cdot 2^{* * *}$ & $-16 \cdot 5^{* * *}$ & $+7 \cdot 0$ & $+6 \cdot 4^{*}$ & $+8 \cdot 5^{* *}$ & $+10 \cdot 0^{* * *}$ & $+2 \cdot 8$ & $+4 \cdot 1$ & $-3 \cdot 3$ \\
\hline \multirow[t]{3}{*}{ Leisure } & Friends and relatives & $21 \cdot 0$ & $+9 \cdot 9 * * *$ & $+0 \cdot 2$ & $+6 \cdot 0$ & $-7 \cdot 4 * *$ & $-3 \cdot 1$ & $-0 \cdot 8$ & $+9 \cdot 8^{* *}$ & $+1 \cdot 4$ & $-2 \cdot 9$ \\
\hline & Restaurant & $9 \cdot 4$ & $-3 \cdot 9$ & $-7 \cdot 9 * * *$ & $+2 \cdot 8$ & $+4 \cdot 2^{*}$ & $+4 \cdot 3$ & $+1 \cdot 5$ & $-3 \cdot 0$ & $-1 \cdot 2$ & $+1 \cdot 4$ \\
\hline & Sports venue & 11.5 & $-5 \cdot 1$ & $+10 \cdot 5 * * *$ & $-0 \cdot 7$ & $+0 \cdot 8$ & $-1 \cdot 0$ & $-6 \cdot 1 * *$ & $-3 \cdot 8$ & $-0 \cdot 1$ & $+0 \cdot 9$ \\
\hline
\end{tabular}

Proportions of individuals who visited the meeting place on an average day shown with variations (in percentage points) by age and regional population density.

$* P<0 \cdot 10 ; * * P<0 \cdot 05 ; * * * P<0 \cdot 01$

${ }^{\text {a }}$ Adult respondents only $(n=443)$. 
percentage points above the average), whereas the older children (7-19 years) more often attended compulsory or upper secondary school $(+44.9$ percentage points) (Table 2). Correspondingly, adult study participants were more likely to be at a workplace, particularly those aged $30-49$ years $(+30 \cdot 7$ percentage points); the obvious exception was the oldest age category (65-90 years) of retirement age $(-15.8$ percentage points). Furthermore, adults were more likely to visit shopping facilities; the differences were especially pronounced for large or specialist stores. Visiting friends and relatives was most common among children aged $0-6$ years ( $+9 \cdot 9$ percentage points) and the least common in the age group $30-49$ years $(-7 \cdot 4$ percentage points). The older children (7-19 years) were least likely to visit restaurants $(-7.9$ percentage points) and most likely to visit sports venues $(+10.5$ percentage points). For obvious reasons, visits to work and school were far less common during weekends, especially for people in concerned age groups. In fact, the only place type that exhibited a substantially larger visit propensity during weekend days was friends and relatives. Even here, however, the difference was quite small (an overall increase of 2 percentage points).

The most tangible difference related to regional population density (defined as geographically defined labour market regions) related to the transport and movement domain. Respondents living in mediumsized and especially small regions were more likely to travel by car $(7.2$ and 17.2 percentage points above the average, respectively), and less prone to use public transport $(-9 \cdot 0$ and -12.6 percentage points, respectively). Conversely, in large regions, there was a higher reliance on public transport $(+9.5$ percentage points) and car use was less prominent $(-9.4$ percentage points). Another notable difference was that, in small labour market regions, visiting friends and relatives was a popular leisure activity $(+9 \cdot 8$ percentage points). On the other hand, visits to public urban space were not surprisingly relatively uncommon $(-5 \cdot 3$ percentage points) in such geographical settings.

There were no significant differences in visit propensity by sex. For instance, males were only slightly more prone to travel by car ( 1.7 percentage points above the average), whereas females opted for using public transport to a larger degree $(+1.5$ percentage points). The figures for education, which only pertain to the adult respondents, distinguish between those respondents who have a higher (university-level) education and those who do not. Although such differences in visit propensity in general were small, there was one exception: respondents with higher education were more likely to make use of public transport $(+5 \cdot 1$ percentage points; $P<0 \cdot 10)$ than those with a lower level of education $(-4 \cdot 2$ percentage points; $P<0 \cdot 10)$.

\section{Meeting place visit characteristics}

There were substantial variations in visit duration by meeting place among the adult respondents. The most time was spent at home and at work; on average, 18.4 and $7 \cdot 6 \mathrm{~h}$, respectively (Table 3 ). Other than that, the average duration of visits to public urban space and places related to leisure-related activities exceeded $1 \mathrm{~h}$. Particularly notable is that, the mean duration of a visit to friends and relatives was about $5 \mathrm{~h}$. The activities that took the least time on average were shopping in large or specialist stores $(0.8 \mathrm{~h})$ and convenience stores $(0 \cdot 4 \mathrm{~h})$.

The number of other persons present also varied considerably; generally, the highest values were found for place types where the average duration was moderate or low. The values refer to the median number of additional persons who were present, and again only pertain to the adult respondents. The two place types, home and car, had the lowest values, each having a median value of one other person present, followed by visits to friends and relatives with a value of 3 . At the other extreme, the values were 40 other persons for public transport, 35 for sports venues and 30 for restaurants. For workplaces, the median number of other persons present was 20. The standard deviation for sports venue is very high, which reflects the fact that this kind of visit sometimes involves being part of the audience to large-scale sports events.

The likelihood of physical contact was by far the highest for four particular place types, namely friends and relatives $(80 \cdot 1 \%)$, followed by home $(73 \cdot 7 \%)$, preschool $(73.3 \%)$ and compulsory or upper secondary school $(71 \cdot 1 \%)$. At work, the likelihood of physical contact was $55 \cdot 8 \%$. The two other place types within the leisure domain, that is, sports venues and restaurants, also had comparatively high contact probabilities: $53 \cdot 8 \%$ and $30 \cdot 8 \%$, respectively. The likelihood of physical contact was lowest when using public transportation or visiting a convenience store.

\section{A typology of generic meeting places of relevance for infectious disease transmission}

The cluster analysis resulted in a typology representing five generic meeting places with similar properties 
Table 3. Characteristics of meeting place visits: duration, number of other persons present and likelihood of physical contact $(\%)$.

\begin{tabular}{|c|c|c|c|c|}
\hline Domain & Meeting place & $\begin{array}{l}\text { Duration (hours) } \\
\text { Mean (s.D.) }\end{array}$ & $\begin{array}{l}\text { Number of other } \\
\text { persons present }^{\mathrm{a}} \\
\text { Median (S.D.) }\end{array}$ & $\begin{array}{l}\text { Physical } \\
\text { contact } \\
\%\end{array}$ \\
\hline \multirow[t]{4}{*}{ Home, work and school } & Home & $18 \cdot 4(4 \cdot 5)$ & $1(2)$ & $73 \cdot 7$ \\
\hline & Work & $7 \cdot 6(2 \cdot 7)$ & $20(111)$ & $55 \cdot 8$ \\
\hline & Pre-school & c & c & $73 \cdot 3$ \\
\hline & $\begin{array}{l}\text { Compulsory or upper } \\
\text { secondary school }\end{array}$ & $\mathrm{c}$ & $\mathrm{c}$ & $71 \cdot 1$ \\
\hline \multirow[t]{3}{*}{ Transport and movement } & Car & $0.9(0 \cdot 8)$ & $1(1)$ & $25 \cdot 8$ \\
\hline & Public transport & $1 \cdot 0(0 \cdot 7)$ & $40(62)$ & $8 \cdot 3$ \\
\hline & Public urban space & $1 \cdot 8(2 \cdot 2)$ & $20(188)$ & $28 \cdot 3$ \\
\hline \multirow[t]{2}{*}{ Shopping } & Convenience store & $0 \cdot 4(0 \cdot 5)$ & $10(25)$ & $8 \cdot 3$ \\
\hline & Large or specialist store & $0 \cdot 8(0 \cdot 8)$ & $21 \cdot 5(133)$ & $18 \cdot 0$ \\
\hline \multirow[t]{3}{*}{ Leisure } & Friends and relatives & $5 \cdot 1(5 \cdot 2)$ & $3(4)$ & $80 \cdot 1$ \\
\hline & Restaurant & $1 \cdot 4(1 \cdot 1)$ & $30(129)$ & $30 \cdot 8$ \\
\hline & Sports venue & $2 \cdot 3(1 \cdot 5)$ & $34 \cdot 5(1495)$ & $53 \cdot 8$ \\
\hline
\end{tabular}

${ }^{\text {a }}$ Adult respondents only $(n=443)$.

${ }^{\mathrm{b}}$ Duration refers to time spent in a meeting place, conditioned on having reported visiting it.

${ }^{\mathrm{c}}$ Figure omitted because of the small number of observations.

with regard to visit propensity and its characteristics in terms of duration, number of other persons present and likelihood of physical contact: (1) the family venue, (2) the fixed activity site, (3) the family vehicle, (4) the trading plaza and (5) the social network hub. Three of the clusters consisted of a single meeting place; the remaining two were made up of four and five place types, respectively (Fig. 1).

The family venue is a clearly distinguishable generic meeting place of its own in the typology. Almost everyone in the survey had been at home, and had spent by far the most time there. This meeting place type has a high likelihood of physical contact, generally occurring among a few permanent members.

The fixed activity site consists of different types of meeting places $(N=4)$ away from home where people regularly spend time on long-term contracted premises for work, education and sports activities. The specific setting visited was largely contingent on age: pre-school or compulsory or upper secondary school among young people; work among adults below retirement age. For these meeting places, visit duration as well as likelihood of physical contact were high. Compared with the family venue, they had lower visit propensity but a higher number of other persons present.

The family vehicle is characterised by a high visit propensity; the second most common place visited on an average day was a car, mostly involving driving or riding in a family automobile. The average duration, however, was low, as was the median number of other persons present. The likelihood of physical contact was the same as that for public urban spaces and restaurants.

There are several meeting places, primarily within the shopping and leisure domains, that people visit to restore their supplies and associate with people. These place types $(N=5)$, which together make up the trading plaza, are convenience stores, large or specialist stores, public transport, restaurants and public urban spaces. Meeting places in the trading plaza are characterised by comparatively low visit propensity, average duration and likelihood of physical contact. The median number of other persons present ranged between 10 (convenience store) and 40 (public urban transport).

The social network hub represents the homes of friends and relatives. At this meeting place type, the likelihood of physical contact is the highest - surpassing even the family venue. Although similar in many ways to the fixed activity site, the social contact hub stands out in that the median number of other persons present was lower.

There were differences between and within the generic meeting places in terms of not only who visits but also concerning who they meet there. Table 4 shows that non-family encounters made up the highest proportion of contacts at work $(100 \cdot 0 \%)$, as well as in restaurants $(91 \cdot 2 \%)$ and large or specialist stores $(87 \cdot 5 \%)$. 


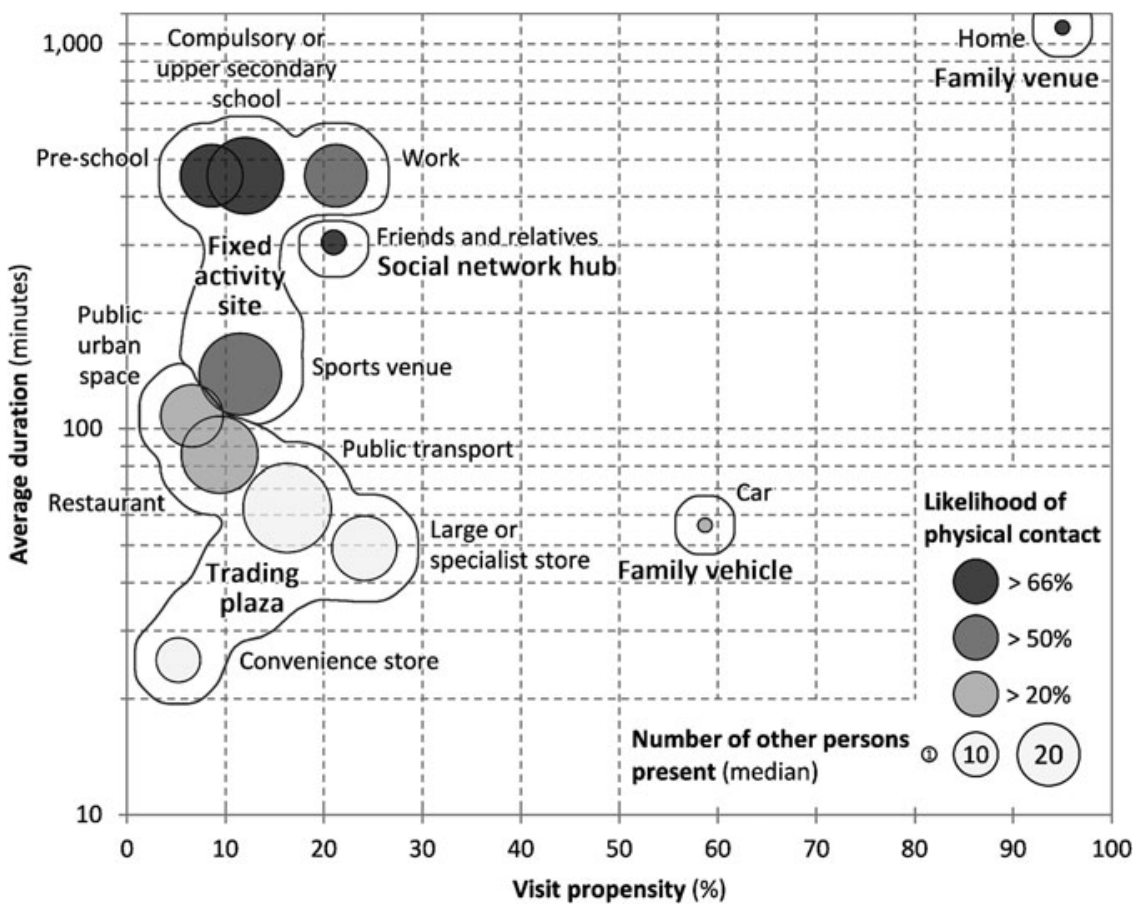

Fig. 1. A typology of generic meeting places of relevance for infectious disease transmission. The $x$-axis represents the propensity of visiting a specific meeting place, whereas the $y$-axis corresponds to the average duration of such visits (expressed in minutes). The size of the circle at each location represents the median number of other persons present; the degree of shading the likelihood of physical contact. ${ }^{4}$

Based solely on the observed distribution of respondents' whereabouts by sex, the expected proportion of intergender physical contact would be about 50\% for all place types. As Table 4 illustrates, certain place types deviated from this expected pattern by exhibiting a lower proportion of physical contact between men and women. In particular, this was the case for the meeting places work $(27 \cdot 0 \%)$, large or specialist stores $(28 \cdot 1 \%)$ and sports venues $(28 \cdot 6 \%)$. Physical contact was most likely to concern a first-time personal encounter in a public urban space $(25.0 \%)$, a large or specialist store $(17 \cdot 9 \%)$ and a sports venue (14.7\%).

\section{DISCUSSION}

This study set out to develop a typology of generic meeting places based on social contact and mixing

4 Given their prominence in the average day of children and adolescents, as well as the possibility of making reasonable estimations concerning missing visit characteristics, the place types pre-school and compulsory or upper secondary school have been included even though some information was missing. Average duration ( $y$-axis) has been assigned that of adult respondents' average time at work, whereas the number of other persons present (circle size) is estimated to be 20 (pre-school) and 30 (compulsory or upper secondary school). of relevance for infectious disease transmission. We derived the typology from an analysis that accounted for four dimensions associated with transmission risk: visit propensity and its characteristics in terms of duration, number of other persons present and likelihood of physical contact. Five generic meeting places were identified, where the representation of the family venue was strong in all four transmission-related dimensions. The thematically related family vehicle had the second highest visit propensity, but lower average duration and likelihood of physical contact. The fixed activity site and trading plaza are both public in nature, but also exhibit important differences. The fixed activity site is characterised by regular, longer visits to specific instances of places, is largely stratified by age and tends to involve persons with whom one is already acquainted. The trading plaza, on the other hand, is characterised by less regular, shorter visits to different instances of meeting places, is more heterogeneous in terms of who visits and tends to involve persons with whom one is not already acquainted. The social network hub also largely involves non-family members. However, like the family venue, it is characterised by a low proportion of first-time contacts. 
Table 4. Contact type characteristics by meeting place: proportion of adult respondents' ( $\mathrm{n}=443)$ physical contacts $(\%)$ that were non-family or intergender, or concerned a first-time personal encounter

\begin{tabular}{|c|c|c|c|c|}
\hline \multirow[b]{2}{*}{ Cluster } & \multirow[b]{2}{*}{ Meeting place } & \multicolumn{3}{|l|}{ Contact type } \\
\hline & & Non-family & Intergender & First time ${ }^{\mathrm{a}}$ \\
\hline Family venue & Home & $19 \cdot 8$ & $68 \cdot 9$ & $0 \cdot 0$ \\
\hline \multirow[t]{4}{*}{ Fixed activity site } & Work & $100 \cdot 0$ & $27 \cdot 0$ & $8 \cdot 3$ \\
\hline & Pre-school & $\mathrm{b}$ & $\mathrm{b}$ & $\mathrm{b}$ \\
\hline & Compulsory or upper secondary school & $\mathrm{b}$ & $\mathrm{b}$ & $\mathrm{b}$ \\
\hline & Sports venue & $81 \cdot 0$ & $28 \cdot 6$ & $14 \cdot 7$ \\
\hline Family vehicle & Car & $\mathrm{n} / \mathrm{a}$ & $\mathrm{n} / \mathrm{a}$ & $\mathrm{n} / \mathrm{a}$ \\
\hline \multirow[t]{5}{*}{ Trading plaza } & Public transport & $\mathrm{n} / \mathrm{a}$ & $\mathrm{n} / \mathrm{a}$ & $\mathrm{n} / \mathrm{a}$ \\
\hline & Public urban space & $80 \cdot 0$ & $50 \cdot 0$ & $25 \cdot 0$ \\
\hline & Convenience store & $\mathrm{b}$ & $\mathrm{b}$ & $\mathrm{b}$ \\
\hline & Large or specialist store & $87 \cdot 5$ & $28 \cdot 1$ & $17 \cdot 9$ \\
\hline & Restaurant & $91 \cdot 2$ & $38 \cdot 2$ & $6 \cdot 5$ \\
\hline Social network hub & Friends and relatives & $76 \cdot 8$ & $50 \cdot 6$ & $1 \cdot 6$ \\
\hline
\end{tabular}

${ }^{a}$ Non-family contacts only.

${ }^{\mathrm{b}}$ Figure omitted because of the small number of observations.

In the preparatory analyses underpinning the typology, we identified the meeting places most commonly visited by the Swedish population, but also found that there were significant differences within the population depending on personal and geographical characteristics. Not surprisingly, persons of working and school age were more likely to be at work and in school, respectively. In addition, young individuals were also more likely to visit sports venues and friends and relatives. With regard to geographical location, defined as labour market regions of different population density, we found that the lower the population density, the higher the reliance on car use and the lower the use of public transport. In addition, individuals living in small labour market regions were more likely to visit friends and relatives. Regarding meeting place visit characteristics, the duration of stay was longest for home, work and public urban spaces, plus leisure-related activities, particularly visits to friends and relatives. The number of other persons present was largely related to degree of 'publicness' of the place: low for home, car and friends and relatives; high, for example, for public transport and sports venues. The likelihood of physical contact while visiting a certain place type was the highest at friends and relatives, followed by the fixed activity sites. The importance of leisure-related activities in facilitating social contacts, especially among young persons, was recently corroborated in a similar study conducted in Russia [26].
It has recently been indicated that demography, particularly in terms of age, is of great importance in explaining infectious disease transmission [18]. While generally largely the case (infectious diseases where infection tend to take place at low age, such as measles, constitute notable exceptions) [27], this inference may lead to important information being neglected in the analyses. Throughout history, meeting places have reflected essential aspects of human social life: how human beings protect themselves and their families from the environment, fulfil their basic needs and learn from each other [28]. One consequence of the current focus on mixing by age is that the spatial representation of meeting places has not been developed to the level that makes such models optimally efficient [29]. It is noteworthy that mixing group representations introduced by, for instance, Elveback et al. [30] and refined by Longini et al. [31], Halloran et al. [10, 32] and others are still widely used in infectious disease modelling, even though their empirical relevance has seldom been verified. It can be questioned, for instance, whether 'family', 'playgroup' and 'community' are sufficient representations of social contact and mixing in today's dynamic societies. In the present study, we used an inductive statistical method to identify the family venue, the fixed activity site, the family vehicle, the trading plaza and the social network hub as spatially explicit generic meeting places. These meeting place types, with their empirically verified characteristics and urban-rural 
variations, provide a current and detailed spatial foundation for modelling of infectious disease transmission based on social contacts and mixing patterns. Previous empirical studies of interpersonal contact vary in their approach, ranging from focusing on arguably the most pertinent place types such as home, work and school $[20,33]$ to incorporating a more extensive set of meeting places [17, 28, 34]. There are also studies that make ambitious efforts to integrate social contact information with data on time spent in specific locations [35-37]. The general impression, however, is that the thematic 'resolution' of the specific places where people meet and interact in everyday life thus far has been coarse, distinguishing between a limited number of meeting place types.

The main contribution of the meeting place typology to infectious disease modelling and control is that it provides a stable yet flexible spatial framework accounting for social contact and mixing, where the social context of the outbreak can be highlighted in light of the actual infectious agent. The typology can be compared with previously identified personal meeting place-adjusted contact profiles [29], also derived by means of cluster analysis. The clusters represent contact profiles related to (1) work ('professional'), (2) school, (3) leisure, (4) the family ('big home'), (5) other places, (6) multiple locations ('mixed') and (7) having a low degree of contact. Evidently, there are both similarities and differences between the approaches. While the meeting place typology focuses on specific spatial locations, the contact profiles describe how particular individuals habitually visit and experience social contacts there. In other words, the typology and profiles meet different needs and purposes. For instance, the meeting place typology can be particularly used in planning of social distancing policies, such as closing of certain meeting places, in the early phases of disease outbreaks. Representation of meeting places that are stable over time is also of particular interest for control of infectious agents for which transmission mainly takes place in settings where infected and susceptible individuals meet regularly and during extended periods of time, for example, for control of tuberculosis $[5,6]$. In contrast, regarding bioterror threats, spread of certain agents such as anthrax is expected to occur through aerosols at large meeting places [38]. By distinguishing the number of visitors and mixing patterns for each type of large meeting place, the typology can be used in modelling the secondary dissemination patterns resulting from such attacks. Finally, the recent outbreak of Ebola in West Africa highlights the importance of expanding the typology of meeting places, when needed, to represent even more specific meeting places with relevance to the infectious agent in questions, such as those related to local funeral practices [39]. The typology presented in this paper can thus provide a pre-processed representation that can support an earlier start of transmission pattern analyses and more rapid response planning when a less known infectious disease is encountered.

Geography also influences social contacts and mixing patterns in a wider sense. Interpersonal contacts are likely to be influenced by the availability of physical places that can function as arenas for such encounters, and the supply of amenities in spatial proximity to the home is highly dependent on population density [22]. There are only a few studies [40] explicitly addressing this link between space on the one hand and social contact and mixing on the other. Another way of expressing the importance of geography in infectious disease diffusion is to acknowledge the fundamental difference between types of meeting places and specific instances of meeting places within each type. People do not actually meet within a type (e.g. work), but mainly within one specific instance of the type (i.e. their own workplace). This applies, in particular, to meeting places with largely permanent members such as those belonging to the family venue and fixed activity site. Not taking this distinction into account blurs the heterogeneity of pairwise social contacts in the population, thus also contributing to an ostensible but illusory unimportance of place and space in infectious disease modelling.

Indeed, the discussion concerning the importance of individual demographic and socio-economic vs meeting place-related characteristics for infectious disease transmission sometimes seems to miss a fundamental point: transmission is not a social construction but a biological, space-related phenomenon requiring physical nearness. While susceptibility can be directly affected by factors such as age, the role of individual attributes is mainly indirect, influencing the selection of specific persons meeting each other. Demographic and socio-economic characteristics help substantially in pinpointing which types of meeting places different persons tend to visit. It is, for instance, more likely that two randomly selected children meet (at school), compared with two randomly selected persons from the same overall population. Much more precise information about the process is gained from knowing which specific instances of meeting places persons 
visit. Individual attributes, however, does not reveal much about the selection into instances, which instead first and foremost comes about based on geography and proximity. A large part of this spatially structured selection of instance-specific meeting place members is often as available empirically from register and/or survey data (or possible to impute) as are demographic and socio-economic characteristics. Consequently, main findings about meeting place types, such as visit propensity and its characteristics in terms of duration, likelihood of physical contact and number of other persons present as presented in this article, provides a foundation for the explicit use of geography in creating relevant instances of meeting places of different types.

Regarding our study, a pertinent issue relates to the validity of social contact and mixing data in understanding the transmission of infectious disease. We based our analyses on a cross-sectional contact diary survey conducted on a representative sample of the Swedish population. The contact diary approach to data capture is one among several available techniques, in itself requiring additional methodological considerations and choices [41]; the other 'families' of methods are direct observation, use of proximity sensors and making inferences from secondary data analysis [42]. Although a relationship reported physical contacts-infection risk cannot be taken for granted, there exists 'strong circumstantial evidence that the contact diary approach, with a definition of contact which includes conversational or physical touch encounters, can capture aspects of social interaction important for the transmission of infection of influenza' [42, p. 2125]. Even so, there are some limitations to our study that should be kept in mind. The form of physical contact is an important factor influencing transmission risk for different types of infectious disease. In our survey, 'physical contact' meant at least actually touching another person, but we did not distinguish between such contacts in more detail. We also mainly took into account the locations where study participants spent the majority of their time. In the vast majority of cases, our survey template managed to capture more or less a whole day, but for a few respondents more time was unaccounted for. In addition, data were collected during the first quarter of the year, and climate may influence social contacts and mixing patterns. In particular, this is likely to be the case in a country like Sweden, where seasons tend to differ substantially in terms of temperature and snow cover.
In conclusion, we set out to develop a typology of generic meeting places of relevance for infectious disease transmission. The typology, comprising five generic meeting places, was derived from an analysis that accounted for four central dimensions associated with transmission risk. However, the fundamental difference between types of meeting places and specific instances of meeting places within each type needs to be acknowledged. Furthermore, the daily mobility between different meeting places, as well as instances of the same type, constitutes a pivotal issue in infectious disease transmission. More research is also warranted on how the typology can be made more detailed by further integrating demographic and socio-economic data related to visits to and contacts in different meeting places. These aspects of social contacts and mixing patterns are not addressed in this study, and thus constitute highly relevant topics for further research.

\section{ACKNOWLEDGEMENTS}

This study was supported by grants from the Swedish Civil Contingencies Agency (T.T., grant no. 20102788); the Swedish Science Council (T.T., grant no. 2008-5252); and the Swedish Governmental Agency for Innovations Systems (VINNOVA) (T.T., grant no. 2011-03231). The funders had no role in study design, data collection and analysis, preparation of the manuscript or decision to publish.

\section{DECLARATION OF INTEREST}

None.

\section{REFERENCES}

1. Cliff A, Haggett P. Time, travel and infection. British Medical Bulletin 2004; 69: 87-99.

2. Colizza V, et al. The role of the airline transportation network in the prediction and predictability of global epidemics. Proceedings of the National Academy of Sciences of the United States of America 2006; 103: 2015-2020.

3. Blower SM, et al. The intrinsic transmission dynamics of tuberculosis epidemics. Nature Medicine 1995; 1: 815-821.

4. Vynnycky E, Fine PEM. The annual risk of infection with Mycobacterium tuberculosis in England and Wales since 1901. The International Journal of Tuberculosis and Lung Disease 1997; 1: 389-396.

5. Dye C, Williams BG. Eliminating human tuberculosis in the twenty-first century. Journal of the Royal Society Interface 2008; 5: 653-662. 
6. Abu-Raddad LJ, et al. Epidemiological benefits of more-effective tuberculosis vaccines, drugs, and diagnostics. Proceedings of the National Academy of Sciences of the United States of America 2009; 106: 13980-13985.

7. Longini IM, et al. Simulation studies of influenza epidemics: assessment of parameter estimation and sensitivity. International Journal of Epidemiology 1984; 13: 496-501.

8. Glass RJ, et al. Targeted social distancing design for pandemic influenza. Emerging Infectious Diseases 2006; 12: 1671-1681.

9. Wu JT, et al. Reducing the impact of the next influenza pandemic using household-based public health interventions. PLoS Medicine 2006; 3: e361.

10. Halloran ME, et al. Modeling targeted layered containment of an influenza pandemic in the United States. Proceedings of the National Academy of Sciences of the United States of America 2008; 105: 4639-4644.

11. Nsoesie EO, et al. A systematic review of studies on forecasting the dynamics of influenza outbreaks. Influenza and Other Respiratory Viruses 2014; 8: 309-316.

12. Timpka $\mathbf{T}$, et al. Population-based simulations of influenza pandemics: validity and significance for public health policy. Bulletin of the World Health Organization 2009; 87: 305-311.

13. Janes CR, et al. Emerging infectious diseases: the role of social sciences. Lancet 2012; 380: 1884-1886.

14. Hägerstrand T. Innovation Diffusion as a Spatial Process. Chicago, IL: University of Chicago Press, 1967.

15. Hudson JC. Diffusion in a central place system. Geographical Analysis 1969; 1: 45-58.

16. Eyler JM. The changing assessments of John Snow's and William Farr's cholera studies. Sozial- und Präventivmedizin 2001; 46: 225-232.

17. Mossong $\mathbf{J}$, et al. Social contacts and mixing patterns relevant to the spread of infectious diseases. PLoS Medicine 2008; 5: e74.

18. Kwok KO, et al. Social contacts and the locations in which they occur as risk factors for influenza infection. Proceedings of the Royal Society of London B: Biological Sciences 2014; 281: 20140709.

19. Sayer LC. Gender, time and inequality: trends in women's and men's paid work, unpaid work and free time. Social Forces 2005; 84: 285-303.

20. Danon L, et al. Social encounter networks: characterizing Great Britain. Proceedings of the Royal Society of London B: Biological Sciences 2013; 280: 20131037.

21. Cohen J. Statistical Power Analysis for the Behavioral Sciences. Hillsdale, NJ: Lawrence Erlbaum, 1988.

22. Haugen K, et al. Proximity, accessibility and choice: a matter of taste or condition? Papers in Regional Science 2012; 91: 65-84.

23. Statistics Sweden (http://www.scb.se/statistik/_publikationer/OV9999_2011A01_BR_X20BR1101.pdf). Accessed 26 April 2017.

24. Brown LD, Cai TT, Dasgupta A. Confidence intervals for a binomial proportion and asymptotic expansions. Annals of Statistics 2002; 30: 160-201.

25. Romesburg C. Cluster Analysis for Researchers. Raleigh, NC: Lulu Press, 2004.
26. Ajelli M, Litvinova M. Estimating contact patterns relevant to the spread of infectious diseases in Russia. Journal of Theoretical Biology 2017; 419: 1-7.

27. Merler S, Ajelli M. Deciphering the relative weights of demographic transition and vaccination in the decrease of measles incidence in Italy. Proceedings of the Royal Society of London B: Biological Sciences 2014; 281: 20132676.

28. Polanyi K. The economy as instituted process. In: Polanyi K, Arensberg CM, Pearson HW, eds. Trade and Market in the Early Empires: Economies in History and Theory. Glencoe, IL: Free Press, 1957, pp. 243-269.

29 Kretzschmar M, Mikolajczyk RT. Contact profiles in eight European countries and implications for modelling the spread of airborne infectious diseases. PLOS ONE 2009; 4: e5931.

30. Elveback LR, et al. An influenza simulation model for immunization studies. American Journal of Epidemiology 1976; 103: 152-165.

31. Longini IM, et al. Containing pandemic influenza with antiviral agents. American Journal of Epidemiology 2004; 159: 623-633.

32. Halloran ME, et al. Community interventions and the epidemic prevention potential. Vaccine 2002; 20: 3254-3262.

33. Potter GE, et al. Estimating within-school contact networks to understand influenza transmission. Annals of Applied Statistics 2012; 6: 1-26.

34. Read JM, Eames KT, Edmunds WJ. Dynamic social networks and the implications for the spread of infectious disease. Journal of the Royal Society Interface 2008; 5: 1001-1007.

35. Zagheni E, et al. Using time-use data to parameterize models for the spread of close-contact infectious diseases. American Journal of Epidemiology 2008; 168: 1082-1090.

36. Iozzi F, et al. Little Italy: an agent-based approach to the estimation of contact patterns-fitting predicted matrices to serological data. PLoS Computational Biology 2010; 6: e1001021.

37. Fumanelli L, et al. Inferring the structure of social contacts from demographic data in the analysis of infectious diseases spread. PLoS Computational Biology 2012; 8: e1002673.

38. Tang JW, et al. Aerosol-transmitted infections: a new consideration for public health and infection control teams. Current Treatment Options in Infectious Diseases 2015; 7: 1-26.

39. Frieden TR, et al. Ebola 2014: new challenges, new global response and responsibility. New England Journal of Medicine 2014; 371: 1177-1180.

40. Moore J, Carrasco JA, Tudela A. Exploring the links between personal networks, time use, and the spatial distribution of social contacts. Transportation 2013; 40: 773-788.

41. Bolton KJ, et al. Influence of contact definitions in assessment of the relative importance of social settings in disease transmission risk. PLoS ONE 2012; 7: e30893.

42. Read JM, et al. Close encounters of the infectious kind: methods to measure social mixing behaviour. Epidemiology and Infection 2004; 140: 2117-2130. 